\title{
Bakterien als Prädiktoren des Kolonkarzinoms?
}

Die Zusammensetzung der Darmflora kann möglicherweise ein erhöhtes Risiko, am Kolonkarzinom zu erkranken, anzeigen.

- Mikrobiologen in Florida werteten die medizinische Anamnese und Daten zu den Ernährungsgewohnheiten von 91 Probanden aus. Von diesen Testpersonen konnten auch jeweils eine Stuhlprobe und mehrere Kolonbiopsate untersucht werden. Die Zusammensetzung der Darmflora wurde mit der von 30 Personen verglichen, bei denen mindestens ein Darmpolyp nachgewiesen worden war.

Bestimmte Bakterien wurden nur im Stuhl von Personen mit Polypen, andere nur in dem von Personen ohne Polypen gefunden. Bei Polypenträgern wurde vermehrt Eubacterium ramulus nachgewiesen, während Ruminococcus sp. bei Personen ohne Polypen überwog. In den Biopsien von Probanden mit Polypen wurde häufiger Acidovorax sp. nachgewiesen. Es fanden sich noch weitere Bakterien, die entweder bei Polypenträgern oder bei Darmgesunden überwogen, die aber noch näher charakterisiert werden müssen.

\section{Kommentar}

Möglicherweise kann man demnächst mit einer einfachen mikrobiologischen Untersuchung einer Stuhlprobe Patienten erkennen, die besonders kolonkarzinomgefährdet sind. Denkbar wäre auch, dass das Kolonkarzinomrisiko durch eine Diät, die das Wachstum bestimmter Bakterien begünstigt bzw. hemmt, reduziert werden kann.

K. MALBERG .

- T. Culpepper et al.

110th General Meeting of the American Society for Microbiology, San Diego, CA. 23.-27.5.2010

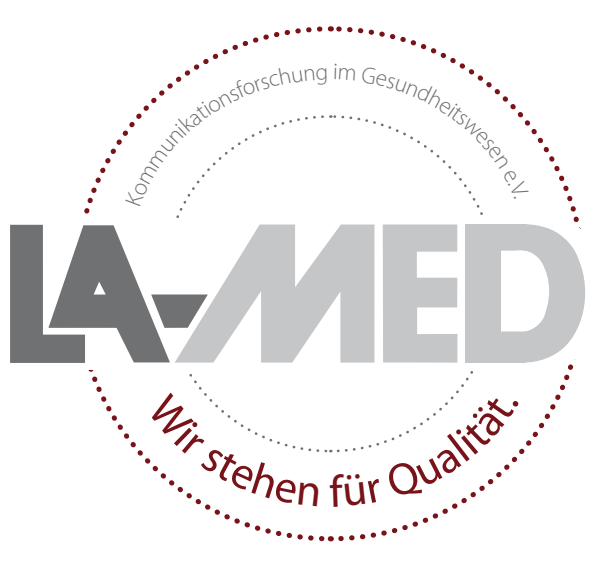

\section{Sie lesen Qualität}

Damit das auch so bleibt, befragen wir Sie in Kooperation mit tns infratest in den nächsten Wochen.

Ihr Urteil ist uns wichtig. Bitte nehmen Sie teil!

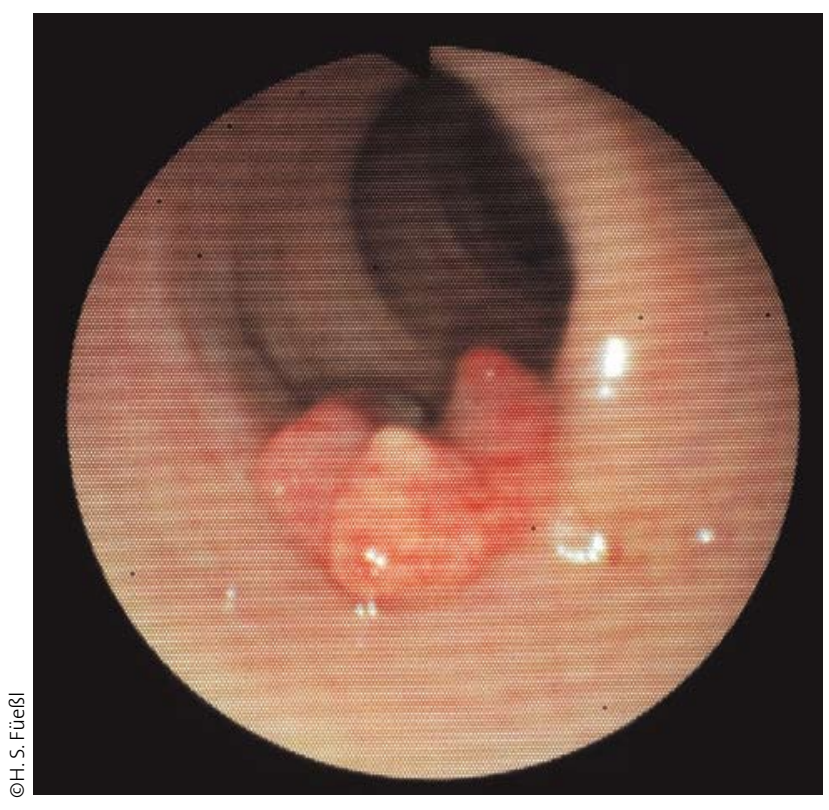

Zeigt die Darmflora Polypen an, bevor sie karzinomatös entarten? 